\title{
Do Active Labor Market Policies Help Unemployed Workers to Find and Keep Regular Jobs?
}

\author{
By: Jan C. van Ours
}

Working Paper Number 289

February 2000 


\title{
Do Active Labor Market Policies Help Unemployed Workers to Find and Keep Regular Jobs?
}

\author{
Jan. C. van Ours, Department of Economics, Tilburg University, \\ The Netherlands, CentER for Economic Research, Institute for \\ Labour Studies (OSA), William Davidson Institute, IZA and CEPR
}

\begin{abstract}
Acknowledgements:
The author is grateful for the financial support from the Volkswagen Foundation and Phare Ace Program of the European Commission and for the help of Martina Lubyova in collecting the data and in providing information about the institutional characteristics of the Slovak labor market. The author thanks participants of the June 1999 ZEW-conference on Econometric Evaluation and the November 1999 IZA-CEPR workshop on program evaluation, in particular Denis Fougère for comments on a previous version of the paper.
\end{abstract}

\begin{abstract}
This paper uses an administrative dataset to analyze to what extent active labor market policies in the Slovak Republic have been beneficial for unemployed workers. The focus is on two types of temporary subsidized jobs and on training. Short-term subsidized jobs seem to be the most efficient active labor market policy. Workers that are or have been on a short-term subsidized job have a higher job finding rate than other unemployed workers have and once they find a job they have a lower job separation rate than workers that have not been on a short-term subsidized job. Long-term subsidized jobs have a negative effect on the job finding rate and no effect on the job separation rate. The positive effect of training on the job finding rate of unemployed workers may have to do with reversed causality: some workers enter a training program only after they are promised a job. Training does not seem to affect the job separation rate.
\end{abstract}

Keywords: unemployment, active labor market policy, duration models 


\section{J. C. van Ours}

\section{Introduction}

Active labor market policies (ALMP) aim to improve the labor market position of unemployed workers. In many countries training and subsidized jobs are important elements of ALMP programs. Subsidized jobs, both in the market sector and the government sector affect the job opportunities of unemployed workers because of the increased number of jobs available. Furthermore, they may upgrade individual unemployed workers when there is a training element involved. The knowledge from training courses and the work experience that unemployed workers collect on a subsidized job may also make them more valuable for employers. Employers in search for new employees may prefer workers who have been on a training course or worked on temporary subsidized jobs to other unemployed workers. If they find a regular job more quickly training and temporary subsidized jobs can be considered as a "treatment" for unemployed workers.

This paper studies the treatment effects of training programs and subsidized jobs that were part of the Slovak program of ALMP. The focus is on the individual treatment effects. So there is no evaluation of possible crowding out phenomena by which treatment may increase the job finding rate of "treated" unemployed workers but only at the expense of non-treated unemployed workers. Nor is there an evaluation of the dead weight loss of the temporary subsidized jobs, which is that some of the treated unemployed workers would have found a job even without treatment.

Slovakia has about 2.2 million employed workers and a 1997 GDP per capita (purchasing power parity) of $\$ 8,600$. The Slovak labor market is one of the transitional labor markets of Central and Eastern Europe (see Svejnar (1999) for an overview). Like many other countries with a transitional economy, Slovakia experienced a sharp increase of unemployment at the initial stage of the transition. In the course of 1991, unemployment increased from practically zero to 300,000 persons which corresponded to an unemployment rate of about 12\% (OECD 1996).

In the course of the 1990s the Slovak government introduced a range of ALMP. Important elements of these ALMP were temporary subsidized jobs known as socially purposeful jobs (SPJ) and publicly useful jobs (PUJ). SPJ were mainly created in the private sector and concerned higher qualified functions while PUJ were low ranking jobs in the public sector best described as "community works" (OECD (1996)). ALMP were introduced in 1991 and gradually developed into a comprehensive system of more than eight basic types of programs. Until the end of 1996 the ALMP in Slovakia contained the following measures: SPJ, PUJ, 


\section{Active labor market policies in Slovakia}

retraining, counseling, sheltered workplaces for the disabled, subsidies for shortened working hours and places for school-leavers. SPJ were the most important throughout the period, both in terms of number of created jobs and expenditures. They were followed by PUJ and retraining. The last major reorganization occurred in 1997 when SPJ and PUJ were combined into one program of subsidized jobs.

In Lubyova and Van Ours (1999) the effects of PUJ, SPJ and training on the transition rate from unemployment to a regular job are investigated. The results of this study are discussed in more detail below. The main purpose of the current paper is to study the effects of ALMP more closely, both by extending the previous analysis and by investigating additional effects. I investigate whether the exit rate to regular jobs increases if an unemployed enters a PUJ, a SPJ or a training program. Furthermore, I investigate whether the separation rate from a new job is related to whether or not the worker previously participated in an ALMP. I use a sample of 3 Slovak districts of which I have detailed labor market information with respect to the workers that started their unemployment spell in 1993. I focus on the labor market position of male workers.

The paper is set up as follows. Section 2 provides stylized facts about the system of passive and active labor market policies in Slovakia. I also discuss the results from a previous study on the effects of Slovak ALMP. Section 3 describes the data and the sampling procedure. Section 4 presents the statistical model and Section 5 presents the estimation results. Section 6 concludes.

\section{Labor market policies}

The Slovak Republic has a well-educated labor force. In 1994 only $14 \%$ of the Slovak labor force had primary or less education, $74 \%$ had secondary education and $12 \%$ had a high education (OECD (1996)). Furthermore, participation rates are high. The participation rate of males in 1994 was $83 \%$ and of females $71 \%$.

There are big differences with respect to the extent to which Slovak workers are confronted with unemployment. In 1994 the unemployment rate of workers aged 15-24 was $29 \%$, for workers aged 25-49 it was $12 \%$, while for the age group 5059 it was $8 \%$. Furthermore, there are big differences between educational categories with unemployment rates being lower for higher educated workers: The unemployment rate of workers with basic or no education was $28 \%$, while for academics it was 3\%. Finally, there are big differences between regions, with the unemployment rate of $4 \%$ in Bratislava being the lowest and rates of $25-30 \%$ in the Eastern parts of Slovakia being the highest.

The system of unemployment benefits in the Slovak Republic has been discussed elsewhere (for a detailed description of institutions I refer the reader to OECD (1996)). Therefore, I only give a summary of the key features of the system. 


\section{J. C. van Ours}

In 1993 workers who lost their job were entitled to unemployment benefits if they were registered at the labor office and had 12 months of work experience during the previous 3 years. The entitlement period lasted 6 months. In 1995 the entitlement period was made dependent on the age of the worker.

Unemployed who exhausted their unemployment benefits eligibility or who were not eligible for unemployment benefits or whose household income did not reach the minimum guaranteed income while collecting unemployment benefits were entitled to social assistance benefits. Eligibility was based on a means test and a benefit was only given when the household income was below the minimum living standard (MLS). The structure of social assistance benefits was the same for unemployed and others. For members of households consisting of two adults the replacement ratio in case of a minimum wage job was about $80 \%$. As soon as children are involved the replacement ratio for minimum wage jobs was $100 \%$. Even for average wage jobs the replacement ratio for adults with children and unemployment benefits was no less than about $80 \%$. After transfer to the social assistance benefits their replacement ratio was about $50-60 \%$ (for more details see Lubyova and Van Ours $(1997,1998)$ ).

The remainder of this section gives a brief description of active labor market policies and of the evaluation studies on the effects of ALMP.

\subsection{Active labor market policies}

Active labor market policies consist of a range of measures from subsidized jobs to training. We focus here on SPJ, PUJ and training. The SPJ program has been the most extensive one among Slovak ALMP programs both in terms of expenditures and participants. SPJ were subsidized jobs in the private sector. The concept of SPJ and the rules of administration have undergone numerous revisions as the authorities learned how to tailor the programs to labor market conditions. In 1991 SPJ were considered to be every job created on the basis of an agreement with the labor office by an employer in production, business or other activities aimed at making profits. In 1992 the profit-seeking requirement was eliminated and the requirement that the job had to be occupied by registered unemployed was introduced. The latter was partially relaxed in 1994 when the school-leavers, persons younger than 18 years and those who would be full-time self-employed under SPJ were allowed to participate without prior registration. The main forms of support introduced in 1991 were subsidies, interest repayments and loans, later reduced to 2-years loans and subsidies. The minimum duration of SPJ was introduced in 1992 and set to 2-years period. In case of lay-off or quit, the job had to be occupied by another registered unemployed within 30 days.

Publicly useful jobs were designed mostly for lower qualified workers for a limited period of time. In 1991 PUJ were introduced as short-term employment opportunities created on the basis of agreements between labor offices and non- 


\section{Active labor market policies in Slovakia}

profit employers (for example, organs of state administration, municipalities, and local administration). The requirement for non-profit orientation of the employer was canceled in 1992. State budgetary organizations and state contributory (partial budgetary) organizations were excluded from PUJ programs in 1994. The upper limit for financial support was originally set at the wage costs of the participant, later extended to cover also participant's social insurance contributions. The maximum duration of PUJ in 1991 was 6 months. Given that the participation renewed unemployment benefit entitlement, many unemployed workers were shifting between PUJ and open unemployment. Therefore, the maximum duration of PUJ was raised to 9 months in 1994 and to 12 months in 1995. The stocks were strongly built up after two major inflows of about the same size, which occurred in the financing boom of 1992, and in the first half of 1995. The latter inflow was a result of changed priorities in 1995 - more means were put into PUJ, partly at the expense of other programs.

Training of unemployed workers has been used relatively modestly. Where possible, retraining of employees in enterprises was preferred to retraining of unemployed by labor offices. The average share of unemployed in the total number of retrained persons was typically 60 to $70 \%$; the share of retrained persons in the total number of unemployed was typically less than 5\%. In 1994 the average duration of a retraining course was 8 weeks, the overall range spanning 4 to 19 weeks. The rate of subsequent job-placement was rather high. This may be due to the ex-ante promise of job-placement required by many labor offices in the light of severe shortage of available vacancies.

The implementation of ALMP was in the hands of the Public Employment Service (PES) that had a network of district offices where every district office had a number of local centers. So, the services were never far away (OECD (1996)). Although priority of placement was given to long-term unemployed workers, the target group of the wage subsidies was not limited to the long-term unemployed. Every unemployed person who could not get a normal job was entitled to a subsidized job offered through the PES system. According to the OECD (1996) the incentive to establish a subsidized job usually came from interested employers. Among the subsidized jobs were jobs that required no special training and education, including caretaking, cleaning, kitchen work and unskilled jobs in general. The creation of subsidized jobs was a matter of negotiation between employers and PES. The wage subsidy was granted to individuals but paid to the employer. The wage was comparable to other workers that had a low skilled industrial job and was usually at the minimum wage or somewhat above. This means that for some workers the replacement rate was quite high. If someone refused a job offered by the PES he or she may have gotten a benefit sanction imposed but the labor offices were usually reluctant to use this instrument.

In 1997 the structure of ALMP programs was substantially reformed. A new act on employment, effective since January 1997, stipulated the following ALMP measures: retraining, support of job creation, support of employment of specific 


\section{J. C. van Ours}

target groups, support for prevention of layoffs, support for maintenance of existing jobs, support for elaborating proposals for revitalization of employment, support for employment of disabled. More attention was given to the measures of a preventive nature, as well as to targeting of the measures to specific groups (disabled, older people, long-term unemployed, young workers and school leavers). The original SPJ and PUJ were formally unified into one program of subsidized jobs, although some distinction between the two types of jobs was preserved.

\subsection{Evaluation of the effects of ALMP}

There have been some studies on the impact of ALMP in transition economies, but there is not an abundant number. From an overview of studies on labor-market reforms in transition economics Boeri (1997) concludes that active policies, such as subsidized employment schemes and public work programs have not been very successful. According to Boeri this may have to do with the phenomenon that slots in training courses are often offered to job seekers with rather favorable labor market characteristics who would have found a job anyway. Furthermore, participation in ALMP may stigmatize the participants, which will reduce their chances of finding a regular job.

With respect to the subsidized jobs in Slovakia the long-term effects for participating workers are considered to be unclear. According to the OECD (1996) it is not clear to what extent workers that have a subsidized job requalify for later employment is the competitive sector. Nevertheless the OECD (1996) expresses some hope of positive effects from the simple fact that subsidized workers hold a normal position in society as long as the subsidy lasts.

Lubyova and Van Ours (1999) investigate to what extent it is beneficial for unemployed workers who want a regular job to enter an ALMP-program, which is defined as an SPJ, a PUJ or a training program. They do separate analyses for males and females. Their estimation results indicate that female, lower educated and older unemployed workers have a worse labor market position, both in terms of the speed with which they find regular jobs as in terms of the speed with which they enter ALMP-programs. Those workers who have a better position when it comes to finding regular jobs are also in a better position to enter an ALMPprogram. The ALMP-programs seem to be complementary to the regular labor market rather than compensating for bad labor market characteristics. Furthermore, it turns out that selectivity is important in the transition processes. For both males and females there are two groups of apparently identical individuals that have different transition rates to both regular jobs and ALMPprograms. There is one group of workers of about $10 \%$ that has a low transition rate to a regular job and a high transition rate to an ALMP-program. Another group of unemployed workers of about $90 \%$ has a higher transition rate to a regular job and a low transition rate to an ALMP-program. Selectivity in the 


\section{Active labor market policies in Slovakia}

transition to ALMP-programs is an important phenomenon. If selectivity is not accounted for the estimated treatment effect of ALMP-programs is negative. If selectivity in the inflow into ALMP-programs is accounted for, it is found that workers that enter these programs benefit from it. After entering an ALMPprogram the exit rate to a regular job increases with $150 \%$. From an additional sensitivity analysis Lubyova and Van Ours (1999) conclude that this effect is mainly due to the positive effect of training and PUJ. For SPJ they find a negative effect on the transition rate from unemployment to a job. The analysis in Lubyova and Van Ours (1999) is limited in the sense that there is no distinction between the transition rates to the separate ALMP-programs. The large positive effect of training may come from the fact that unemployed that enter a training program get the ex ante promise of a regular job. Then, training is not a treatment to increase the transition rate from unemployment to a job, but the promise of a job is a 'treatment' to increase the inflow into training.

\section{Data}

The data used in our analysis come from the unemployment registers of labor offices in three Slovak districts. The first district is Bratislava (excluding the capital Bratislava) with a December 1993 unemployment rate of $4.1 \%$, the second district is Dolny Kubin with an unemployment rate of $12.9 \%$ and the third district is Bardejov with an unemployment rate of $19.3 \%$.

In the selected districts the data collection was exhaustive, i.e. all the registered unemployed were selected. Several types of information are used in order to reconstruct individual histories. An individual history consists of a sequence of spells representing three possible labor market states: employment, unemployment and out of labor force. In addition to that the spells of participation in SPJ and PUJ programs are identified. The information about the last unemployment spell comes directly from the unemployment register, which contains also information about the personal characteristics of job applicants. Due to the overwriting of records in case of repeated registration, the unemployment register does not contain information on previous unemployment history. Therefore, unemployment archives had to be used in order to reconstruct the information on previous unemployment spells. In addition to the unemployment information, separate files are used that contain information about previous employment or out of the labor force spells prior to every registration. Finally, information about dates and duration of ALMP programs are used.

From the unemployment register and unemployment archives an inflow sample was selected of all the unemployed that became registered in the course of 1993. The censoring point is April 1998. By combining the information from the

\footnotetext{
${ }^{1}$ The analysis is restricted to SPJ, PUJ and training, ignoring other ALMP programs.
} 


\section{J. C. van Ours}

unemployment register the unemployment archives and information on ALMP, individual histories were constructed, each ending at the above-mentioned censoring date. The use of 1993 inflow is justified by the relative stability in the institutional set-up of the labor market (major reforms occurred at the beginning of 1992 and 1995). Another reason was a sufficient time period elapsed before the censoring point in order to avoid large shares of censored spells. In the analysis I use information about the length of the first spell of unemployment that started in 1993 and if this spell ended about the labor market status after unemployment. If the spell ended in a transition to a job the unemployment spell was considered to be completed. If the spell ended in a transition to an ALMP-program the unemployment duration was considered to continue until another transition occurred either to a job or back to unemployment. When a transition to a job happened the unemployment spell was considered to be complete. When a transition occurred back to unemployment the spell was still considered to be incomplete. In the analysis the duration of unemployment up to a transition to an ALMP-job or to training is also important. This duration is the search period until an ALMP measure is met. If the spell did not end or ended in a transition to out of the labor force the unemployment spell is considered to be right censored.

Table 1 Transitions in the sample; numbers of workers in different subsequent labor market states ${ }^{\text {a) }}$

\begin{tabular}{|c|c|c|c|}
\hline State 1 & State 2 & State 3 & \begin{tabular}{|l|} 
State 4 \\
\end{tabular} \\
\hline \multirow[t]{12}{*}{$\mathrm{U}(5057)$} & \multirow[t]{3}{*}{ PUJ (332) } & \multirow[t]{2}{*}{ E (128) } & $\mathrm{U}(91)$ \\
\hline & & & $\mathrm{C}(37): \mathrm{E}(26), \mathrm{c}(11)$ \\
\hline & & $\begin{array}{l}\text { C (204): unknown (7), SPJ (1), } \\
\text { PUJ (40), U (114), c (42) }\end{array}$ & \\
\hline & \multirow[t]{3}{*}{ SPJ (275) } & \multirow[t]{2}{*}{$\mathrm{E}(177)$} & $\mathrm{U}(87)$ \\
\hline & & & $\begin{array}{l}\text { C (90): SPJ (1), E (52), } \\
\mathrm{c}(37)\end{array}$ \\
\hline & & $\begin{array}{l}\text { C (98): unknown (30), SPJ (3), } \\
\text { U (61), c (4) }\end{array}$ & \\
\hline & \multirow[t]{3}{*}{$\operatorname{Tr}(179)$} & \multirow[t]{2}{*}{$\mathrm{E}(132)$} & $\mathrm{U}(70)$ \\
\hline & & & $\begin{array}{l}\text { C (52): SPJ (5), E (40), } \\
\text { c (17) }\end{array}$ \\
\hline & & $\begin{array}{l}\text { C (47): unknown (20), SPJ (11), } \\
\text { PUJ (5), U (5), Tr (6) }\end{array}$ & \\
\hline & \multirow[t]{2}{*}{$\mathrm{E}(3525)$} & $\mathrm{U}(2452)$ & \\
\hline & & $\begin{array}{l}\text { C (1073): unknown (1), } \\
\text { E (776), c (296) }\end{array}$ & \\
\hline & $\begin{array}{l}\text { C (746): unknown (462) } \\
\text { U (240), c (44) }\end{array}$ & & \\
\hline
\end{tabular}

a) $\mathrm{E}=$ regular job, $\mathrm{U}=$ unemployed, $\mathrm{PUJ}=$ publicly useful job, $\mathrm{SPJ}=$ socially purposeful job, $\mathrm{Tr}$ $=$ training, $\mathrm{C}=$ considered to be censored, $\mathrm{c}=$ actually censored 


\section{Active labor market policies in Slovakia}

The explanatory variables I use in the analysis refer to age, education and marital status. Appendix 1 gives details about our dataset. As shown there, on average $35 \%$ of the unemployed in our sample was younger than 30 years, $59 \%$ had a lower education and $58 \%$ was married. Apart from the unemployment rate the largest differences between the unemployed in the three districts seem to be age or age-related. In Bratislava on average the unemployed are older than in the other two districts, they are lower educated and have a higher share of married man.

Table 1 gives some indication about the transitions in labor market status that were used in the analysis. Over the period of observation 332 unemployed entered a PUJ, 275 entered a SPJ, 179 entered a training program and 3525 unemployed found a regular job without having been on an ALMP program. For 746 unemployed the unemployment spell is right censored. There are several reasons for the spells to be considered as right censored. Some of them really are right censored in the sense that at the end of the sample period they were still unemployed. Other workers have left unemployment with unknown destination. Then, there are people who left unemployment and re-entered immediately, probably for administrative reasons.

Furthermore, Table 1 shows that of the 332 unemployed workers that have been on a PUJ 128 entered a regular job, 177 entered a regular job after being on a SPJ and 132 entered a regular job after being on a training program. The remaining spells are considered to be right censored unemployment spells. A lot of unemployed workers that have found a regular job during the sampling period have lost their job and reentered unemployment. There are 776 workers that have found a new job after their first one. The estimations are based on the duration of the first job which we assume to be right censored at the start of the second job. Note that in total only $9 \%$ of the transitions go to an unknown labor market state.

\section{Figure 1 Quarterly transition rates; three Slovak districts}

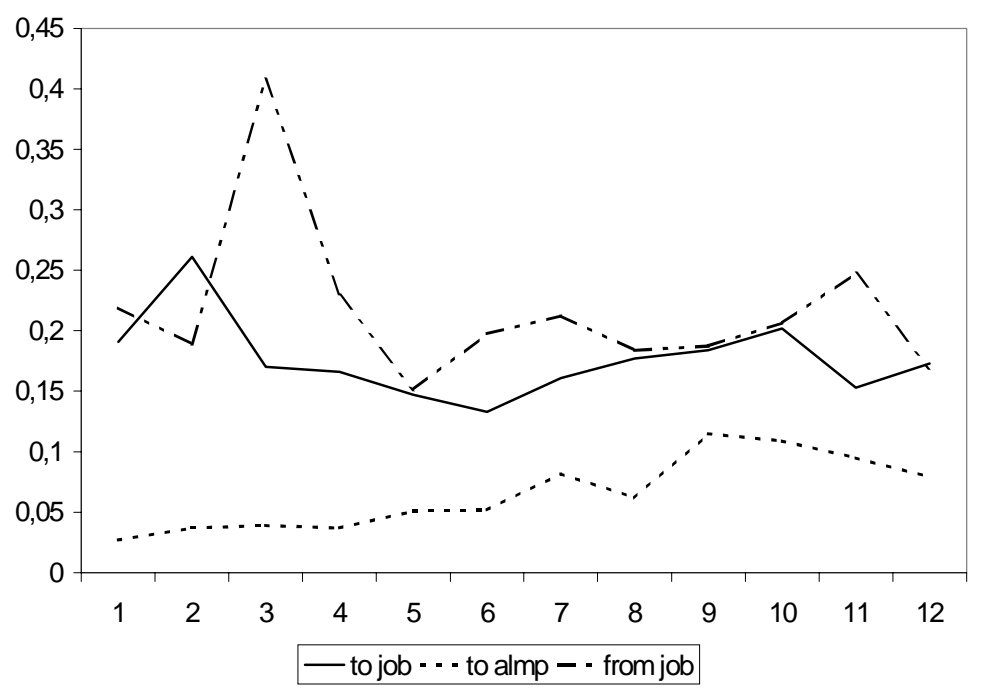




\section{J. C. van Ours}

Figure 1 shows quarterly transition rates. From this figure it appears that apart from a peak in the second quarter the transition rate from unemployment to a regular job is sort of constant over the duration of unemployment. The entrance rate into ALMP programs increases over the first eight quarters and fluctuates after that. The transition rate from a regular job back to unemployment has a peak in the third quarter but is sort of constant before and after the third quarter. The transition rates from unemployment to a regular job and from a regular job back to unemployment have about the same magnitude.

\section{Statistical model}

We consider an ALMP program as a 'treatment' that may affect the behavior of the unemployed workers. In order to establish the effect of an ALMP program on the exit rate from unemployment to a regular job we have to set-up a model that accounts for possible selectivity in the inflow into ALMP. Heckman et al. (1999) gives an overview of the relevant issues when one wants to establish treatment effects. There have been many treatment effect studies but studies that estimate the effects of the treatment in the context of an event history model of labor force dynamics are raref. In our model we exploit information with respect to the duration of unemployment, the duration of the stay in an ALMP, the destinations after that and the duration of a subsequent employment spells. In multivariate duration models the variation in the durations at which treatment is administered to individuals, and data on the corresponding pre- and post-treatment durations can be exploited to identify the treatment effect. The intuition is as follows. Consider the transition rate from unemployment to a regular job, which is affected by unobserved heterogeneity that has a discrete distribution with two points of support. Consider also the transition rate from unemployment to an ALMP that is affected by a similar type of unobserved heterogeneity. If the two types of unobserved heterogeneity are correlated this means that conditional on observed characteristics there are four groups of individuals that differ in terms of transition to a job (high/low) and transition to an ALMP (high/low). Conditional on observed characteristics each of these four groups is homogenous. So, within the groups selectivity of the inflow into an ALMP cannot be present. Therefore, we are able to estimate the unbiased effect of the ALMP on the transition rate from unemployment to a regular job if we can identify the unobserved heterogeneity in both the transition rate to a regular job and the transition rates to ALMP. This means that the data should contain information about all relevant transitions over some period of time, which they do.

\footnotetext{
2 An early example of the use of duration models in an evaluation study is Ridder (1986).

${ }^{3}$ If all unemployed would enter an ALMP at the same elapsed duration of unemployment we could not identify potential selectivity.
} 


\section{Active labor market policies in Slovakia}

A formal proof of the identification of the treatment effect is given in Abbring and Van den Berg (1998). Van den Berg (2000) presents an overview of duration models and has a general discussion on the use of duration models in estimating treatment effects. He indicates that in order to avoid biased estimates of the impact of ALMPs on unemployment durations it is necessary that individuals do not behave in anticipation to future events.

Examples of the use of multivariate duration models in evaluation studies are Abbring, Van den Berg and Van Ours (1997) and Van den Berg, Van der Klaauw and Van Ours (1998 4 In these studies the effect of benefit sanctions on the transition rate from unemployment to employment is modeled. Here too, the issue of selectivity is very important. Again, selectivity is accounted for by simultaneously modeling the exit rate out of unemployment and the rate by which unemployed get a sanction imposed. Both studies find a significant positive effect of benefit sanctions on the transition rate from unemployment to a job. In the study by Van den Berg, Van der Klaauw and Van Ours (1998) it is shown that if unobserved heterogeneity is not accounted for, no effect of sanctions is found. Furthermore, if only the transition rate from unemployment to a job is taken into consideration the presence of unobserved heterogeneity cannot be detected. Therefore, it seems to be important to take the possible correlation between the unobserved components of the transition rate to a job and the transition rate to the sanction state into account.

I do not only consider the effect of ALMP on the transition rate from unemployment to a job but also consider the effect of ALMP on the separation rate once workers have found a job. In this respect the current paper is in the line of Gritz (1993) and Bonnal et al. (1997). Gritz (1993) considers the impact of training on the employment experience of American youths. He distinguishes between three labor market states, unemployment, employment and training and estimates the coefficients of the six related transition rates. To account for selectivity he models unobserved heterogeneity assuming a discrete distribution with a finite number of points of support. He finds five points of support to be optimal, so there appear to be five classes of individuals in the unobserved heterogeneity distribution. Bonnal et al. (1997) study the effect of public employment policies set up in France during the 1980's. These policies intended to improve the labor market position of young unskilled workers. Bonnal et al. use individual labor market transition data distinguishing between six labor market states: unemployment, permanent job, temporary job, public employment policy job, out-of labor force, and attrition. This means that there are 25 possible labor market transitions. Their statistical model is of the mixed proportional hazard (MPH) type, with piecewise constant duration dependence. To reduce the complexity of the model restrictions are imposed on the distribution of unobserved heterogeneity. Two alternative specifications of the distribution of unobserved

\footnotetext{
${ }^{4}$ A related study is Holm, Van den Berg and Van Ours (1998).
} 


\section{J. C. van Ours}

heterogeneity are investigated. In the first specification the unobserved heterogeneity components are generated by a common normally distributed random variable. In this case the correlation between the unobserved components can only equal 0,1 or -1 . In the second specification the unobserved components are assumed to have discrete multivariate distributions with a finite number of points of support. Because a six-dimensional discrete distribution involves a large number of parameters Bonnal et al. (1997) use a two-factor loading model with four points of support. The second specification is much more flexible than the first. From their estimation results it appears that participation in labor market programs is highly selective in the model with the second specification of unobserved heterogeneity, while no selection effect is found in the model with the first specification of unobserved heterogeneity. Apparently, a flexible specification of unobserved heterogeneity is very important.

To establish the effect of selectivity I start with a simple duration model and subsequently introduce more complexity. The baseline model has for every transition rate a proportional specification with a flexible baseline hazard. Differences between unemployed individuals in the transition rate from unemployment to a job can be characterized by the observed characteristics $\mathrm{x}$, the elapsed duration of unemployment itself, and a variable indicating whether or not the individual started participating in an ALMP. I assume $\mathrm{x}$ to be time-invariant. Furthermore, $\mathrm{t}_{\mathrm{a}}(\mathrm{a}=$ PUJ, SPJ, retraining) is the time at which the individual starts participating in an ALMP and $\mathrm{I}\left(\mathrm{t}_{\mathrm{a}}<\mathrm{t}\right)$ is the dummy variable indicating whether the individual has already started participating. I use a similar specification for the transition rate to PUJ, SPJ and training and for the transition rate from regular jobs back to unemployment. In the latter transition rate I include a dummy variable $d_{a}$ that indicates if a worker has participated in an ALMP program $\left(\mathrm{d}_{\mathrm{a}}=1\right)$ or not $\left(\mathrm{d}_{\mathrm{a}}\right.$ $=0$ ). The transition rate from unemployment to a regular job at time $\mathrm{t}$ conditional on $\mathrm{x}$ and $\mathrm{t}_{\mathrm{a}}$, the transition rate to SPJ, PUJ or training at time $\mathrm{t}$ conditional on $\mathrm{x}$ and the transition rate from a regular job back to unemployment at time $t$ conditional on $\mathrm{x}$ and $\mathrm{d}_{\mathrm{a}}$ can be specified as follows:

$\theta_{\text {ue }}\left(\mathrm{t} ; \mathrm{x}, \mathrm{t}_{\mathrm{a}}\right)=\lambda_{\text {ue }}(\mathrm{t}) \cdot \exp \left(\mathrm{x}^{\prime} \beta_{\text {ue }}+\delta_{\text {ue }, \mathrm{a}} \mathrm{I}\left(\mathrm{t}_{\mathrm{a}}<\mathrm{t}\right)\right)$

$\theta_{\mathrm{a}}(\mathrm{t} ; \mathrm{x})=\lambda_{\mathrm{a}}(\mathrm{t}) \cdot \exp \left(\mathrm{x}^{\prime} \beta_{\mathrm{a}}\right)$

$\theta_{\text {eu }}\left(t ; x, d_{a}\right)=\lambda_{\text {eu }}(t) \cdot \exp \left(x^{\prime} \beta_{\text {eu }}+\delta_{\text {eu,a }} \cdot d_{a}\right)$

where the $\lambda_{j}(t)$-functions, $j=u e, a$, eu represent individual duration dependence, $\delta_{\text {ue,a }}$ measures the effect that participation in an ALMP has on the transition rate from unemployment to a regular job and $\delta_{\text {eu,a }}$ measures the effect of previous

\footnotetext{
${ }^{5}$ As indicated above in the calculation of the unemployment duration I add the time spend during ALMP. So, if $t_{1}$ is the unemployment spell until entering an ALMP-program, $t_{2}$ is the time spend in the program and $t_{3}$ is the time unemployed after the program and before entering a regular job, total unemployment duration $t=t_{1}+t_{2}+t_{3}$.
} 


\section{Active labor market policies in Slovakia}

participation in an ALMP on the separation rate from a regular job. In both cases I assume the treatment to be an incidence effect (Gritz (1993) There could be a lot of aspects of the ALMP that potentially affect the transition rate to a regular job and the job separation rate, but I only take the effect of the participation in an ALMP into account. Flexible duration dependence is modeled by using step functions:

$\lambda_{\mathrm{j}}(\mathrm{t})=\exp \left(\sum_{\mathrm{k}}\left(\lambda_{\mathrm{j}, \mathrm{k}} \mathrm{I}_{\mathrm{k}}(\mathrm{t})\right)\right.$

where $\mathrm{j}=\mathrm{ue}, \mathrm{a}$, eu is an indicator for the type of transition, $\mathrm{k}(=1, . .4)$ is a subscript for time-intervals and $\mathrm{I}_{\mathrm{k}}(\mathrm{t})$ are time-varying dummy variables that are one in subsequent time-intervals. I distinguish four time intervals: 1-2 quarters, 34 quarters, 4-8 quarters and 8+ quarters Because a constant term is also estimated I normalize $\lambda_{\mathrm{ue}, 1}=\lambda_{\mathrm{a}, 1}=\lambda_{\mathrm{eu}, 1}=0$.

The conditional density functions of the completed unemployment durations $t_{u}$, the completed durations until entrance of an ALMP $t_{a}$ and the completed employment durations $\mathrm{t}_{\mathrm{e}}$ can be written as

$f_{\text {ue }}\left(\mathrm{t}_{\mathrm{u}} ; \mathrm{x}, \mathrm{t}_{\mathrm{a}}\right)=\theta_{\text {ue }}\left(\mathrm{t}_{\mathrm{u}} ; \mathrm{x}, \mathrm{t}_{\mathrm{a}}\right) \exp \left(-{ }_{0}{ }^{\text {tu }} \theta_{\text {ue }}\left(\mathrm{s} ; \mathrm{x}, \mathrm{t}_{\mathrm{a}}\right) \mathrm{ds}\right)$

$f_{\mathrm{a}}\left(\mathrm{t}_{\mathrm{a}} ; \mathrm{x}\right)=\theta_{\mathrm{a}}\left(\mathrm{t}_{\mathrm{a}} ; \mathrm{x}\right) \exp \left(-{ }_{0}{ }^{\mathrm{ta}} \theta_{\mathrm{a}}(\mathrm{s} ; \mathrm{x}) \mathrm{ds}\right)$

$f_{\text {eu }}\left(\mathrm{t}_{\mathrm{e}} ; \mathrm{x}, \mathrm{d}_{\mathrm{a}}\right)=\theta_{\text {eu }}\left(\mathrm{t}_{\mathrm{e}} ; \mathrm{x}, \mathrm{d}_{\mathrm{a}}\right) \exp \left(-{ }_{0} \int{ }^{\mathrm{te}} \theta_{\mathrm{e}}\left(\mathrm{s} ; \mathrm{x}, \mathrm{d}_{\mathrm{a}}\right) \mathrm{ds}\right)$

Since we have an inflow sample and the transition rates are uncorrelated, the loglikelihood $\mathrm{L}$ of the model factorizes where the components are specified as

$\mathrm{L}_{\mathrm{j}}=\mathrm{d}_{\mathrm{j}} \cdot \sum \log \left(f_{\mathrm{j}}\right)+\left(1-\mathrm{d}_{\mathrm{j}}\right) \cdot \sum \log \left(1-\mathrm{F}_{\mathrm{j}}\right)$

where the $F_{j}$ 's are distribution functions, $d_{j}$ is a dummy variable with a value of 1 if the transition $\mathrm{j}$ is completed and a value zero is the duration of the spell is right censored.

In the second model I allow for unobserved heterogeneity to affect the transitions to both a regular job, to one of the ALMP programs and from a job back to unemployment:

$\theta_{\text {ue }}\left(\mathrm{t} ; \mathrm{x}, \mathrm{u}, \mathrm{t}_{\mathrm{a}}\right)=\lambda_{\text {ue }}(\mathrm{t}) \cdot \exp \left(\mathrm{x}^{\prime} \beta_{\text {ue }}+\delta_{\text {ue, }} \mathrm{I}\left(\mathrm{t}\left(\mathrm{t}_{\mathrm{a}}<\mathrm{t}\right)+\mathrm{u}\right)\right.$

$\theta_{\mathrm{a}}\left(\mathrm{t} ; \mathrm{x}, \mathrm{v}_{\mathrm{a}}\right)=\lambda_{\mathrm{a}}(\mathrm{t}) \cdot \exp \left(\mathrm{x}^{\prime} \beta_{\mathrm{a}}+\mathrm{v}_{\mathrm{a}}\right)$

$\theta_{\text {eu }}\left(t ; x, w, d_{a}\right)=\lambda_{\text {eu }}(t) \cdot \exp \left(x^{\prime} \beta_{\text {eu }}+\delta_{\text {eu, }, a} \cdot d_{a}+w\right)$

\footnotetext{
${ }^{6}$ Note that because of this the changes in the length of PUJ-jobs that occured in the course of time do not have to be taken into account explicitly.

7 The intervals were chosen because they are related to the social security system (the workers that became unemployed during 1993 had a UB-entitlement period of 6 months) or because of convention (the border line between short-term and long-term unemployment is 1 year, the border line between long-term and very-long-term is 2 years).
} 


\section{J. C. van Ours}

where $u, v_{a}$ and $w$ are the components of unobserved heterogeneity in the transitions. These components are assumed to follow a discrete distribution with two points of support $\left(\mathrm{p}_{\mathrm{j}}\right.$ and $\left.1-\mathrm{p}_{\mathrm{j}}\right)$. In the second model I assume the unobserved heterogeneity components to be independent. Therefore the conditional density functions and the loglikelihoods are similar to those in (3) and (4).

The basic assumption so far is that the inflow into the ALMP programs is a random process in the sense that it is independent of the process by which unemployed find jobs and subsequently loose jobs. The selection into the treatment-program is assumed to be exogenous and not dependent on unobserved characteristics that also affect the job finding rate or the job separation rate. In other words, conditional on observed characteristics and the duration of unemployment the quality of the unemployed flowing into an ALMP is as good (or as bad) as the quality of the unemployed workers that remain unemployed. Then, if there is an effect of an ALMP $\left(\delta_{\text {ue, a }} \neq 0\right)$, this is a 'true' effect. This effect can go both ways. If $\delta_{\text {ue,a }}<0$ the ALMP has a negative effect on the reemployment hazard, which could be caused by stigmatization. If $\delta_{\mathrm{ue}, \mathrm{a}}>0$ the workers on an ALMP have a higher exit rate to a job than the non-participants. Note that in the specification of the hazard in equations (1) and (5) the effect of an ALMP occurs immediately. Also note that I consider the duration of a stay in an ALMP as extended unemployment duration. This concept does not coincide with the official statistics but I take the point of view of a labor economist: a person is unemployed until he or she finds a regular job or leaves the labor market. A similar line of reasoning holds with respect to possible correlation between the flow into an ALMP and the separation rate from regular jobs. In the first two models I assume that there is no such correlation. Again, if $\delta_{\text {eu,a }}<0$ the ALMP has a negative effect on the separation hazard and thus a positive effect on job tenure. Signaling could cause this effect. Workers that have accepted an ALMP signal their willingness to work. If $\delta_{\mathrm{eu}, \mathrm{a}}>0$ the workers on an ALMP have a higher job separation rate than the non-participants, which could be caused by the fact that the match between workers from an ALMP and a regular job is less efficient.

In the third model the unobserved heterogeneity terms are allowed to be correlated. Now selectivity in the inflow into one of the ALMP programs is accounted for. If unobserved characteristics have a negative effect on the job finding rate and a positive effect on the transition rate to an ALMP, then conditional on the observed characteristics and the elapsed duration of unemployment the average quality of the workers in an ALMP is lower than the average quality of workers who do not enter an ALMP. Then, if one would simply compare the transition rates to regular jobs of both groups one compares workers with unfavorable characteristics and ALMP with workers with more favorable characteristics and no ALMP. Therefore, one would underestimate the true effect of participating in an ALMP. The opposite effect is also possible. One can imagine that the people in control of the entrance to ALMP want their programs to be a success. Therefore they prefer workers with good characteristics to flow into 


\section{Active labor market policies in Slovakia}

their program. This implies that there is a positive correlation between the unobserved heterogeneity components in both transition rates. Then, the effect of an ALMP program is overestimated. $G\left(u, v_{a}, w\right)$ is defined to be the joint distribution of the unobserved characteristics $u, v_{a}$ and $w$. Then, the joint density function of $\mathrm{t}_{\mathrm{ue}}, \mathrm{t}_{\mathrm{a}}$ and $\mathrm{t}_{\mathrm{eu}}$ conditional on $\mathrm{x}$ equals

$$
\begin{aligned}
& f_{\text {ue, }, \text { e eu }}\left(\mathrm{t}_{\mathrm{ue}}, \mathrm{t}_{\mathrm{a}}, \mathrm{t}_{\text {eu }} \mid \mathrm{x} ; \mathrm{u}, \mathrm{v}_{\mathrm{a}}, \mathrm{w}, \mathrm{t}_{\mathrm{a}}, \mathrm{d}_{\mathrm{a}}\right)= \\
& \quad \int_{\mathrm{u}} \int_{\text {va }} \int_{\mathrm{w}} f_{\text {ue }}\left(\mathrm{t}_{\mathrm{ue}} \mid \mathrm{x}, \mathrm{u}, \mathrm{t}_{\mathrm{a}}\right) f_{\mathrm{a}}\left(\mathrm{t}_{\mathrm{a}} \mid \mathrm{x}, \mathrm{v}_{\mathrm{a}}\right) f_{\text {eu }}\left(\mathrm{t}_{\text {eu }} \mid \mathrm{x}, \mathrm{w}, \mathrm{d}_{\mathrm{a}}\right) \mathrm{dG}\left(\mathrm{u}, \mathrm{v}_{\mathrm{a}}, \mathrm{w}\right)
\end{aligned}
$$

Each of the error terms is assumed to follow a discrete distribution with two points of support, and each error term can be correlated to another $\$$. Therefore, $G$ is a discrete distribution of unobserved heterogeneity with eight points of support $\left(\mathrm{u}^{\mathrm{a}}\right.$, $\left.v_{a}^{a}, w^{a}\right),\left(u^{b}, v_{a}{ }^{b}, w^{a}\right),\left(u^{a}, v_{a}{ }^{b}, w^{a}\right),\left(u^{b}, v_{a}^{a}, w^{a}\right),\left(u^{a}, v_{a}^{a}, w^{b}\right),\left(u^{b}, v_{a}{ }^{b}, w^{b}\right),\left(u^{a}, v_{a}{ }^{b}\right.$, $\left.w^{a}\right),\left(u^{b}, v_{a}^{a}, w^{b}\right)$. The associated probabilities are denoted as follows:

$$
\begin{array}{ll}
\operatorname{Pr}\left(\mathrm{u}=\mathrm{u}^{\mathrm{a}}, \mathrm{v}=\mathrm{v}_{\mathrm{a}}^{\mathrm{a}}, \mathrm{w}=\mathrm{w}^{\mathrm{a}}\right)=\mathrm{p}_{1} & \operatorname{Pr}\left(\mathrm{u}=\mathrm{u}^{\mathrm{b}}, \mathrm{v}=\mathrm{v}_{\mathrm{a}}^{\mathrm{b}}, \mathrm{w}=\mathrm{w}^{\mathrm{a}}\right)=\mathrm{p}_{2} \\
\operatorname{Pr}\left(\mathrm{u}=\mathrm{u}^{\mathrm{a}}, \mathrm{v}=\mathrm{v}_{\mathrm{a}}^{\mathrm{b}}, \mathrm{w}=\mathrm{w}^{\mathrm{a}}\right)=\mathrm{p}_{3} & \operatorname{Pr}\left(\mathrm{u}=\mathrm{u}^{\mathrm{b}}, \mathrm{v}=\mathrm{v}_{\mathrm{a}}^{\mathrm{a}}, \mathrm{w}=\mathrm{w}^{\mathrm{a}}\right)=\mathrm{p}_{4} \\
\operatorname{Pr}\left(\mathrm{u}=\mathrm{u}^{\mathrm{a}}, \mathrm{v}=\mathrm{v}_{\mathrm{a}}^{\mathrm{a}}, \mathrm{w}=\mathrm{w}^{\mathrm{b}}\right)=\mathrm{p}_{5} & \operatorname{Pr}\left(\mathrm{u}=\mathrm{u}^{\mathrm{b}}, \mathrm{v}=\mathrm{v}_{\mathrm{a}}^{\mathrm{b}}, \mathrm{w}=\mathrm{w}^{\mathrm{b}}\right)=\mathrm{p}_{6} \\
\operatorname{Pr}\left(\mathrm{u}=\mathrm{u}^{\mathrm{a}}, \mathrm{v}=\mathrm{v}_{\mathrm{a}}^{\mathrm{b}}, \mathrm{w}=\mathrm{w}^{\mathrm{b}}\right)=\mathrm{p}_{7} & \operatorname{Pr}\left(\mathrm{u}=\mathrm{u}^{\mathrm{b}}, \mathrm{v}=\mathrm{v}_{\mathrm{a}}^{\mathrm{a}}, \mathrm{w}=\mathrm{w}^{\mathrm{b}}\right)=\mathrm{p}_{8}
\end{array}
$$

where $0 \leq \mathrm{p}_{\mathrm{i}} \leq 1$ and $\sum_{\mathrm{i}} \mathrm{p}_{\mathrm{i}}=1, \mathrm{i}=1, . ., 8$. The set-up of the likelihood is similar to the one presented in equation (4). Note that because of the introduction of correlated unobserved heterogeneity it is not possible to factorize the likelihood as we did for the previous models, so we have to estimate all the coefficients jointly.

\section{Estimation results}

\subsection{Parameter estimates}

Of all the workers in our sample we have information with respect to the length of the unemployment spell, the destination after the unemployment spell, the length of the subsequent spell, et cetera. On the basis of this information we estimate the coefficients of the models presented in the previous section using the method of maximum likelihood. Apart from the personal characteristics age, education and marital status we also include fixed effects for two of the three districts in the analysis.

Table 2 presents the estimation results for the baseline model. The parameter estimates for the transition rate to a job indicate that age is not relevant for this transition. Furthermore, low educated unemployed workers have a smaller

\footnotetext{
${ }^{8}$ Note that I assume that there is perfect correlation between the unobserved components of the three ALMP-transition rates. This correlation may be perfectly negative of perfectly positive.
} 


\section{J. C. van Ours}

transition rate to a job than workers with an incomplete, secondary or higher education. Married men have a higher job finding rate than their counterparts. In the districts with a high unemployment rate the direct transition to a regular job is smaller than in districts with a lower unemployment rate. There is also some negative duration dependence in the transition rate from unemployment to a job. However it is only the first six months in which the transition rate is significantly higher than later on. Beyond six months the job finding rate is sort of constant. Finally, it appears that unemployed that have entered a PUJ have a significantly higher transition rate to a job than those that did not have a PUJ. Unemployed that entered a SPJ have a lower transition rate to a regular job than those that did not. Unemployed that entered a training program have a substantially higher transition rate to a regular job.

Table 2 Estimation results three districts; males, no unobserved heterogeneity (t-values in parentheses)

$\begin{array}{llllll} & \text { To job } & \text { To PUJ } & \text { To SPJ } & \text { To training } & \text { from job } \\ \text { Age }<30 & -0.01(0.2) & -0.06(0.5) & 0.30(2.1)^{*} & 0.43(2.3)^{*} & -0.13(2.8)^{*} \\ \text { Inc. Sec. ed. } & 0.20(3.7)^{*} & -0.33(1.5) & 0.74(4.1)^{*} & 0.47(2.1)^{*} & -0.15(2.6)^{*} \\ \text { Sec higher ed. } & 0.13(3.4)^{*} & -0.44(2.7)^{*} & 0.59(4.1)^{*} & 0.70(3.9)^{*} & -0.28(5.9)^{*} \\ \text { Married } & 0.17(4.6)^{*} & -0.22(1.8) & 0.43(2.9)^{*} & 0.63(3.4)^{*} & -0.13(2.8)^{*} \\ \text { District 2 } & -0.08(2.1)^{*} & -0.02(0.1) & -0.10(0.7) & -0.11(0.6) & 0.00(0.1) \\ \text { District 3 } & -0.54(10.9)^{*} & -0.12(0.7) & -0.32(1.8) & 0.17(0.8)^{*} & 0.15(2.9)^{*}\end{array}$

\section{Mass points}

$\mathrm{u}^{\mathrm{a}}, \mathrm{v}^{\mathrm{a}}, \mathrm{w}^{\mathrm{a}}$

$$
-2.46(53.7)^{*}-6.80(25.4)^{*}-5.46(29.0)^{*}-6.76(25.2)^{*}-2.75(48.2)^{*}
$$

\section{Duration dependence}

$\begin{array}{llllll}\text { 3-4 Quarters } & -0.25(5.8)^{*} & 1.75(6.4)^{*} & -0.42(2.6)^{*} & 0.42(2.1)^{*} & 0.79(18.5)^{*} \\ \text { 4-8 Quarters } & -0.35(7.8)^{*} & 2.69(10.5)^{*} & -0.56(3.2)^{*} & 0.60(3.0)^{*} & -0.09(1.5) \\ \text { 8+ Quarters } & -0.40(7.2)^{*} & 3.41(13.4)^{*} & -0.65(2.4)^{*} & 0.58(2.2)^{*} & 0.09(1.1)\end{array}$

\section{Treatment effects}

\begin{tabular}{|c|c|c|c|c|}
\hline PUJ & $0.41(4.2)^{*}$ & & & $0.32(3.0)^{*}$ \\
\hline SPJ & $-0.56(8.0)^{*}$ & & & $-0.80(6.0)^{*}$ \\
\hline Training & $1.79(14.3)^{*}$ & & & $-0.05(0.5)$ \\
\hline Loglikelihood & $-14,207.5$ & $-1,676.8$ & $-1,166.0$ & $-9,799.3$ \\
\hline
\end{tabular}

*: At a $5 \%$-level the coefficient is significantly different from zero. 


\section{Active labor market policies in Slovakia}

For the transition rate to a PUJ the only personal characteristic that has a coefficient significantly different from zero is the dummy for secondary and higher education. As was to be expected lower educated unemployed workers have a higher transition rate into PUJ. There is positive duration dependence in the transition rate to PUJ. The transition rate in the first six months is substantially below the one in later periods. SPJ and training have higher entrance rates for younger, higher educated and married unemployed. In many respects the transition rates to SPJ and training are complementary to the transition rate to a regular job.

The job separation rate turns out to be smaller for young workers. Furthermore, the job separation rate decreases with the educational level. And, married workers have a lower job separation rate. With the exception of a higher job separation rate between 6 and 12 months of job tenure there is no duration dependence in the job separation rate. The treatment effect of a PUJ turns out to be positive. This would imply that accepting a PUJ both stimulates the transition rate from unemployment to a job and the job separation rate. So, workers on a PUJ leave unemployment more quickly but also return to unemployment more quickly than their counterparts do. The opposite holds for SPJ. Once unemployed enter a SPJ their transition rate to a regular job decreases, but if they enter a regular job they stay on that job longer. Of course, these results are obtained under the assumption of no presence of unobserved heterogeneity, which also implies that we did not correct for selectivity in the inflow to the ALMP programs.

The estimation results for the second model are shown in Table 3. There appear to be unobserved determinants in three of the five transition rates. There is no unobserved heterogeneity in the transition to a SPJ or to training. With the introduction of unobserved heterogeneity the estimation results for the other transition rates improve, which is easy to see because within each of the transition rates the mass points are significantly different from each other at conventional levels of significance 9 . Within the transition rate from unemployment to a regular job there is conditional on the effects of personal characteristics and the elapsed duration of unemployment a small group of 5\% that has a substantially lower transition rate than the majority has. The transition rate of this small group is only about $20 \%$ of the transition rate of the larger group. Within the transition rate to a PUJ there are also two groups. About two-thirds has a positive transition rate to a PUJ and about one-third has a transition rate of zero. Apparently, there is a group of workers that has no possibility to enter a PUJ. Finally, within the job separation

9 A formal Likelihood-Ratio test is problematic since one of the parameters $\left(p_{j}\right)$ is not identified in the model without unobserved heterogeneity. The difference in the values of the loglikelihoods between the models with and without unobserved heterogeneity is large for the transition rate to a regular job (23.9) and for the job separation rate (38.8). The difference for the transition rate to PUJ is smaller (3.0), but here the probability does not go to an extreme value, while one of the mass points is well defined and the other goes to $-\infty$. Therefore, here too unobserved heterogeneity seems to be present. 


\section{J. C. van Ours}

process there are two groups of about equal size. The differences in job separation rate between these two groups are substantial. One group has a transition rate from employment back to unemployment that is about $10 \%$ of the transition rate of the other group.

Table 3 Estimation results three districts; males, with unobserved heterogeneity in each of the transition rates ( $t$-values in parentheses)

$\begin{array}{llll} & \text { To job } & \text { To PUJ } & \text { From job } \\ \text { Age }<30 & -0.05(1.1) & -0.18(1.2) & -0.01(0.1) \\ \text { Inc. Sec. ed. } & 0.21(3.4)^{*} & -0.33(1.4) & -0.17(2.0)^{*} \\ \text { Sec higher educ. } & 0.15(3.3)^{*} & -0.46(2.5)^{*} & -0.27(4.0)^{*} \\ \text { Married } & 0.17(4.1)^{*} & -0.36(2.5)^{*} & -0.16(2.4)^{*} \\ \text { District 2 } & -0.10(2.5)^{*} & -0.06(0.4) & 0.01(0.1) \\ \text { District 3 } & -0.53(9.7)^{*} & -0.25(1.3) & 0.27(3.6)^{*}\end{array}$

Mass points

$\begin{array}{lccc}\mathrm{u}^{\mathrm{a}}, \mathrm{v}^{\mathrm{a}}, \mathrm{w}^{\mathrm{a}} & -2.40(39.8)^{*} & -6.22(20.4)^{*} & -4.28(26.4)^{*} \\ \mathrm{u}^{\mathrm{b}}, \mathrm{v}^{\mathrm{b}}, \mathrm{w}^{\mathrm{b}} & -4.49(5.3)^{*} & -\infty(-) & -2.07(20.9)^{*}\end{array}$

\section{Duration dependence}

$\begin{array}{llll}\text { 3-4 Quarters } & -0.22(4.9)^{*} & 1.76(6.4)^{*} & 1.45(21.9)^{*} \\ \text { 4-8 Quarters } & -0.27(4.8)^{*} & 2.74(10.6)^{*} & 1.24(8.7)^{*} \\ \text { 8+ Quarters } & -0.02(0.2) & 3.75(13.5)^{*} & 1.54(9.4)^{*}\end{array}$

\section{Treatment effects}

$\begin{array}{lccc}\text { PUJ } & 0.43(4.1)^{*} & & 0.24(1.4) \\ \text { SPJ } & -0.35(3.1)^{*} & & -1.58(8.7)^{*} \\ \text { Training } & 1.79(12.3)^{*} & & -0.00(0.0) \\ \text { Unobs. het. probability } & & & \\ \mathrm{p}_{\mathrm{j}} & 0.95(28.4)^{*} & 0.66(9.4)^{*} & 0.48(13.6)^{*} \\ \text { Loglikelihood } & -14,183.6 & -1,797.0 & -9,760.5\end{array}$

The coefficients of the personal characteristics are hardly affected. The main changes in the parameter estimates refer to the coefficients of the duration dependence parameters and the coefficients that represent the treatment effects. In the estimates with unobserved heterogeneity the transition rate from unemployment to a job goes up after two years and is even higher than in the first six months in stead of being lower as in the previous estimates. The duration dependence of the transition rate to PUJ is hardly affected by the introduction of 
Active labor market policies in Slovakia

unobserved heterogeneity, but the job separation rate is. Whereas in the baseline model there was hardly any duration dependence, now the job separation rate in the first six months is significantly smaller than it is in later periods.

Table 4 Estimation results three districts - correlated unobserved heterogeneity; males (tvalues in parentheses) $)^{\text {a) }}$

$\begin{array}{llllll} & \text { To job } & \text { To PUJ } & \text { To SPJ } & \text { To training } & \text { From job } \\ \text { Age }<30 & -0.07(1.5) & -0.07(0.5) & 0.24(1.5) & 0.44(2.4)^{*} & 0.00(0.0) \\ \text { Inc Sec. ed. } & 0.21(3.3)^{*} & -0.36(1.5) & 0.74(3.8)^{*} & 0.47(2.0)^{*} & -0.22(2.7)^{*} \\ \text { Sec higher educ. } & 0.17(3.6)^{*} & -0.61(3.4)^{*} & 0.61(3.9)^{*} & 0.70(3.8)^{*} & -0.30(4.5)^{*} \\ \text { Married } & 0.18(4.1)^{*} & -0.40(2.6)^{*} & 0.45(2.9)^{*} & 0.62(3.3)^{*} & -0.19(2.9)^{*} \\ \text { District 2 } & -0.11(2.5)^{*} & -0.03(0.2) & -0.10(0.7) & -0.11(0.6) & 0.01(0.1) \\ \text { District 3 } & -0.56(9.9)^{*} & -0.23(1.2) & 0.28(1.5) & 0.16(0.8) & 0.29(3.8)^{*}\end{array}$

\section{Mass points}

$\mathrm{u}^{\mathrm{a}}, \mathrm{v}_{\mathrm{a}}^{\mathrm{a}}, \mathrm{w}^{\mathrm{a}} \quad-2.36(40.0)^{*}-6.01(19.6)^{*} \quad-\infty(-) \quad-6.64(18.8)^{*} \quad-4.23(29.4)^{*}$

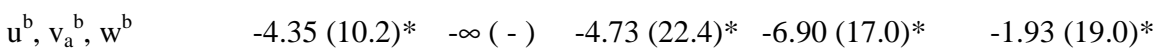

Duration dependence

$\begin{array}{lllll}\text { 3-4 Quarters } & -0.20(4.4)^{*} & 1.72(5.8)^{*}-0.37(2.3) * & 0.42(2.1)^{*} & 1.51(21.8)^{*} \\ \text { 4-8 Quarters } & -0.22(3.9)^{*} & 2.67(9.6)^{*}-0.51(2.9)^{*} & 0.59(3.0)^{*} & 1.27(9.6)^{*} \\ \text { 8+ Quarters } & 0.12(1.1) & 3.64(12.5)^{*}-0.76(2.7)^{*} & 0.59(2.2)^{*} & 1.51(10.4)^{*}\end{array}$

Treatment effects

$\begin{array}{llc}\text { PUJ } & 0.59(3.8)^{*} & -0.53(2.7)^{*} \\ \text { SPJ } & -0.45(3.5)^{*} & -0.26(1.6) \\ \text { Training } & 1.80(10.5)^{*} & -0.09(0.4)\end{array}$

Unobs. het. probability

$\begin{array}{llll}\mathrm{p}_{1} & 0.07(2.4)^{*} & \mathrm{p}_{5} & 0.38(10.2)^{*} \\ \mathrm{p}_{2} & 0.0(-) & \mathrm{p}_{6} & 0.06(3.1)^{*} \\ \mathrm{p}_{3} & 0.45(10.3)^{*} & \mathrm{p}_{7} & 0.02(-) \\ \mathrm{p}_{4} & 0.02(1.8) & \mathrm{p}_{8} & 0.0(-)\end{array}$

Loglikelihood 


\section{J. C. van Ours}

The introduction of unobserved heterogeneity hardly affects the treatment effects in the transition from unemployment to a job. However, there is a substantial change in the PUJ-treatment effect from a job back to unemployment. Whereas in the baseline model this treatment effect was significantly positive it is now positive, but not significantly different from zero. Of course, these results are obtained under the assumption that there is no correlation between the unobserved components.

Table 4 shows the estimation results for the third model in which the unobserved components are allowed to be correlated, so it allows for selectivity in the inflow into ALMP. In the estimation the unobserved components of the three ALMP transition rates are assumed to be perfectly correlated. Now, it appears that there is unobserved heterogeneity in the SPJ transition rate, which was not found in the previous estimates. Furthermore, it appears that in terms of unobserved components workers either have a positive PUJ transition rate or a positive SPJ transition rate. The estimation results indicated that there is selectivity in the inflow into ALMP 10 .

Two probabilities out of the eight that are distinguished go to zero so a discrete distribution with six points of support remain 11 The largest group has a share of $45 \%$ and consists of workers that have a higher transition rate from unemployment to a job, a zero transition rate to a PUJ, positive transition rates to SPJ and training and a low transition rate from a regular job back to unemployment than there counterparts have.

Conditional on the personal characteristics and the time spent in unemployment or employment this is the group of workers that has the best labor market characteristics. They find a job quickly and once they have found it they stick to it. The second largest group has a share of $38 \%$. This is the group that has a high transition rate from unemployment to a regular job, a positive transition rate to a PUJ and training, a zero transition rate to a SPJ and a high job separation rate. So, this group leaves unemployment relatively quickly, but also returns to unemployment relatively quickly.

If we look at the unobserved heterogeneity distributions of each of the transition rates separately we see that they are different from those in Table 3 . Within the job finding rate we now have a group of $92 \%$ that has a high value and $8 \%$ that has a low value. Within the transition rate to a PUJ we have a group of $47 \%$ with a

${ }^{10}$ The sum of the loglikelihood-values in Table 3 and those of the SPJ transition rate and training transition rate in Table 2 is $-28,583$.9, which means that there is a difference in loglikelihood-value of 24.4 between the model with correlated unobserved heterogeneity and the one with independent unobserved heterogeneity. Again, no formal Likelihood-Ratio test can be applied. However the difference between the two likelihood-values seems large enough to reject the hypothesis of independent unobserved heterogeneity.

${ }^{11}$ This means that two out of the possible eight combinations we distinguish do not exist. 


\section{Active labor market policies in Slovakia}

positive value and $53 \%$ with a zero value, meaning that this group has no probability to enter a PUJ. Finally, within the job separation rate we have groups of about equal size, $54 \%$ with a low value and $46 \%$ with a much higher value.

Comparing the coefficients in the models with independent and with correlated unobserved heterogeneity it is obvious that the estimates of the coefficients of the personal characteristics are hardly affected. Also, the pattern of duration dependence is approximately the same. What changes mostly are the treatment effects. For example, there is a negative correlation between the unobserved components of the transition rate to a regular job and the transition rate to a PUJ. This means that conditional on other determinants the groups that have a lower transition rate to a job have a higher transition rate to PUJ. If this negative correlation is not accounted for the effect a PUJ has on the transition rate to a regular job is underestimated. Therefore, the treatment effect as measured according to the third estimates is larger than the one we measured in the first two models. Overall there is a positive correlation between the unobserved components in the transition to a PUJ and the separation rate. This means that conditional on the other determinants workers that enter a PUJ are more likely to have short job tenures. If this correlation is not accounted for the effect of a PUJ on the job separation rate is overestimated. In fact, as shown in Table 4 the treatment effect is now negative: those workers that have been on a PUJ are more likely to have long job tenures than the workers that have not been on a PUJ. The positive effect of a PUJ on the exit rate out of unemployment and the negative effect on the job separation rate could have to do with signaling. By accepting a PUJ the unemployed worker signals a positive attitude towards work. Apparently, this leads both to a higher job finding rate and to a better quality of the match between worker and job. If only the first effect would be observed it would be difficult to give a clear interpretation. Unemployed that have been on a PUJ could lower their reservation wage for a regular job or increase their search intensity because they not want to stay on the PUJ. Now that a PUJ also effects the job tenure I think both treatment effects are related to employers' recruitment behavior.

With respect to the job finding rate the treatment effect of SPJ is negative irrespective of the model used. Apparently, workers that enter a SPJ reduce their efforts to find a regular job. This may have to do with the long-term character of a SPJ, which makes it from the perspective of the individual unemployed worker a good substitute for a regular job. The job separation rate is not affected by a previous SPJ-position, which indicated that workers that take a SPJ neither benefit from it nor are they stigmatized because of it.

These results with respect to SPJ and PUJ seem to be counterintuitive since PUJ were focused on disadvantaged groups while SPJ were targeted on unemployed with favorable labor market prospects. However, in the empirical model the explanatory variables account for some of the differences with respect to labor market prospects. And, perhaps the SPJ were too much like regular jobs. The PUJ 


\section{J. C. van Ours}

effects could have to do with signaling. The workers on PUJ may have unfavorable labor market characteristics, by accepting a PUJ the unemployed worker signals a positive attitude towards work.

The estimation results in Table 4 also indicate that training has a big impact on the job finding rate. Workers that enter a training program have a job finding rate that is 6 times as high as the job finding rate of other workers. I think this effect is unbelievably high and could indicate reversed causality: some unemployed only enter a training program after they have been promised a job 12 Finally, training does not make an unemployed more valuable to an employer since the job separation rate is not affected by previous participation in a training program.

\subsection{Additional analysis}

From the estimation results it is clear that the introduction of unobserved heterogeneity terms irrespective of whether they are correlated or not does not affect the estimates of the coefficients of the three transition rates very much. The main difference is in the measurement of the treatment effect of PUJ and SPJ on the job separation rate. In the baseline model there is no unobserved heterogeneity, a significant positive PUJ-treatment effect and a significant negative SPJtreatment effect. In the second model with uncorrelated unobserved heterogeneity components an insignificant positive PUJ-treatment is found while the SPJtreatment effect remains significantly negative. In the third model with correlation between the unobserved heterogeneity components I find a significant negative PUJ-treatment effect while the SPJ-treatment effect does not differ significantly from zero.

PUJ seem to be the most efficient ALMP. Workers that have been on a PUJ have a larger job finding rate and a smaller job separation rate. In the study by Bonnal et al. (1997) it is shown that the specification of the distribution of unobserved heterogeneity may affect the estimation results. To illustrate the importance of a flexible specification of unobserved heterogeneity I also estimated a model in which perfect correlation between the unobserved heterogeneity components is imposed. This means that in stead of six groups there are two groups of workers that conditional on the observed characteristics and the elapsed duration of unemployment or employment are homogeneous within but different between.

Imposing two-point heterogeneity I find a group of $56 \%$ that has a positive transition rate to a PUJ, a zero transition rate to SPJ and a small job separation rate. The other group of $44 \%$ has a zero transition rate to a PUJ, a positive transition rate to SPJ and a much higher job separation rate. Both groups hardly differ in their transition rate to training and their job finding rate. The effect on the

\footnotetext{
12 Note that this also violates the non-anticipation condition necessary to avoid biased estimates of the impact of ALMPs on unemployment durations.
} 


\section{Active labor market policies in Slovakia}

job finding rate of the ALMP programs is not much different than before. However the effects that a PUJ and a SPJ have on the job separation rate are different than before. The job separation PUJ-treatment effect is opposite to the effect as measured in the model without perfect correlation of the unobserved heterogeneity components whereas unlike before a SPJ now has a significant negative effect on the job separation rate. Apparently, if too heavy restrictions are imposed on the distribution of unobserved heterogeneity estimated treatment effects may be severely biased.

Table 5 Simulation results, effects of a PUJ; survival probabilities (\%)

$$
\text { Type } a \quad \text { Type } b \quad \text { Average }
$$

Job finding No PUJ PUJ No PUJ PUJ No PUJ PUJ

$\begin{array}{lcccccc}\text { After 6 months } & 50 & 50 & 90 & 90 & 54 & 54 \\ \text { After 1 year } & 28 & 14 & 83 & 75 & 34 & 21 \\ \text { After 2 year } & 16 & 4 & 76 & 62 & 23 & 10\end{array}$

Job separation

$\begin{array}{lcccccc}\text { After 6 months } & 93 & 96 & 49 & 65 & 72 & 81 \\ \text { After 1 year } & 66 & 78 & 2 & 9 & 35 & 45 \\ \text { After 2 years } & 51 & 66 & 0 & 2 & 27 & 35\end{array}$

a) Young, low educated, married worker in the district Bratislava; the PUJ starts after 6 months

To illustrate the size of the effects of a PUJ some simulations results are shown in Table 5. The simulations refer to a young, low educated, married worker in the district of Bratislava. There is a distinction between type $a$ and type $b$ workers. As shown in Table 5 type $a$ workers have a survival probability after 6 months of $50 \%$ and a survival probability after 1 year of $28 \%$. If a type $a$ worker enters a PUJ at 6 months of unemployment his survival probability after 1 year is $14 \%$. So, a PUJ has a big impact of the survival probabilities of unemployed workers. Type $b$ workers have a much weaker labor market position. Their survival probability after 1 year is $83 \%$. If a type $b$ worker enters a PUJ at 6 months his survival probability after 1 year equals $75 \%$. Here too, the effect is substantial. For the (weighted) average of the two types of workers a similar impact of a PUJ is found. The average survival probability after 6 months is $54 \%$ and after 1 year it is $34 \%$. If a worker enters a PUJ at six months his average survival probability after 1 year is $21 \%$. Table 5 also shows the treatment effect of a PUJ on the job separation rate. The two types of workers differ substantially in their survival rate. Of type $a$ workers $93 \%$ still has his job after 6 months, of type $b$ workers this is $49 \%$. After 


\section{J. C. van Ours}

1 year of type $a$ workers $66 \%$ still has his job, while of type $b$ workers only $2 \%$ still has his job. On average after 1 year $35 \%$ of the workers still has his job, which is $45 \%$ for those workers that have been on a PUJ. Again, the treatment effect is substantial.

\section{Conclusions}

This paper studies job finding and job separation rates of male workers in three districts in the Slovak Republic. Job finding rates appear to be higher for higher educated and married workers. Job separation rates decrease with the educational level and are lower for married workers.

The main interest is in the effect that ALMP-programs have on job finding and job separation rates. PUJ, SPJ and training programs are used as a treatment to stimulate unemployed workers to find a regular job. It is important to evaluate whether the treatment actually works. The main issue in an evaluation study of this kind is the possible endogeneity of the inflow into the treatment program. It could be that unemployed workers that flow into an ALMP program have unobserved characteristics that are different from those that do not. It could be that workers that go to an ALMP are less able to find a regular job than otherwise identical non-participants in an ALMP are. Then a straightforward comparison of the two groups in terms of job finding rates leads to an underestimation of the effect of an ALMP. It is also possible that workers that go to an ALMP are less able to keep a regular job than otherwise identical non-participants in an ALMP are. Then a straightforward comparison of the two groups in terms of job separation rate leads to an overestimation of the effect of an ALMP. To account for this type of selectivity transition rate models are estimated that allow for the three transition rates to be interdependent.

The transition rate into a PUJ, a SPJ or training, the transition rate from unemployment to a regular job and the job separation rate may be influenced by unobserved variables that could be correlated. One of the findings of the paper is that it is very important to use a flexible specification of the correlation structure. SPJ appear to have a negative effect on the job finding rate and no effect on the job separation rate. The positive effect found for training on the job finding rate of unemployed workers may have to do with reversed causality: some workers enter a training program only after they are promised a job. Training does not seem to affect the job separation rate. PUJ seem to be the most efficient active labor market policy. Workers that are or have been on a PUJ have a higher job finding rate than other unemployed workers have and once they find a job they have a lower job separation rate than workers that have not been on a PUJ. These effects could have to do with signaling. By accepting a PUJ the unemployed worker signals a positive attitude towards work. Apparently, this leads both to a higher job finding rate and to a better quality of the match between worker and job. 
Active labor market policies in Slovakia

\section{References}

Abbring, J.H., Van den Berg, G.J., Van Ours, J.C. (1997): “The Effect of Unemployment Insurance Sanctions on the Transition Rate from Unemployment to Employment". Working Paper Tinbergen Institute, Amsterdam/Rotterdam.

Abbring, J.H., Van den Berg, G.J. (1999): “The Non-Parametric Identification of Treatment Effects in Duration Models". mimeo, Vrije Universiteit Amsterdam.

Boeri, T. (1997): "Labor-market Reforms in Transition Economies". Oxford Review of Economic Policy, 13, 126-140.

Bonnal, L., Fougère, D., Sérandon A. (1997): "Evaluating the Impact of French Employment Policies on Individual Labor Market Histories". Review of Economic Studies, 64, 683-713.

Gritz, R.M. (1993): "The Impact of Training on the Frequency and Duration of Employment". Journal of Econometrics, 57, 21-51.

Heckman, J.J., LaLonde, R.J., Smith, J.A. (1999): "The Economics and Econometrics of Active Labor Market Programs". in: Ashenfelter O., Card, D. (eds.), Handbook of Labor Economics, volume III, North-Holland.

Holm, A., Van den Berg, G.J., Van Ours, J.C. (1999): "Does work experience help to become a medical specialist". Discussion Paper 9919, CentER for Economic Research, Tilburg University.

Lubyova, M., Van Ours, J.C. (1997): "Unemployment Dynamics and the Restructuring of the Slovak Unemployment Benefit Systems". European Economic Review, 41, 923-934.

Lubyova, M., Van Ours, J.C. (1998): "Work Incentives and Other Effects of the Transition to Social Assistance: Evidence from the Slovak Republic". Empirical Economics, 23, 1/2: 121-154.

Lubyova, M., Van Ours, J.C. (1999): "Effect of Active Labor Market Programs on the Transition Rate from Unemployment into Regular Jobs in the Slovak Republic". Journal of Comparative Economics, 27, 90-112.

Organization for Economic Co-operation and Development (1996): Labor Markets and Social Policies in the Slovak Republic, Paris: OECD.

Puhani, P.A. (1998): “Advantage through Training? A Microeconomic Evaluation of the Employment Effects of Active Labor Market Programs in Poland". ZEWDiscussion Paper no. 98-25, Mannheim.

Ridder, G. (1986): “An event history approach to the evaluation of training, recruitment, and employment programs". Journal of Applied Econometrics, 11, 109-126. 


\section{J. C. van Ours}

Svejnar, J. (1999): Labor Markets in the Transitional Central and East European Economies". in: Ashenfelter O., Card, D. (eds.), Handbook of Labor Economics, volume III, North-Holland.

Van den Berg, G.J., Van der Klaauw, B., Van Ours, J.C. (1998): "Punitive Sanctions and the Transition Rate from Welfare to Work", Discussion Paper CentER for Economic Research no. 9856, Tilburg University.

Van den Berg, G.J. (2000): "Duration Models: Specification, Identification, and Multiple Durations", in: Heckman, James J., and Leamer, Edward (eds.), Handbook of Econometrics, Volume V, North-Holland, forthcoming. 
Active labor market policies in Slovakia

\begin{abstract}
Appendix 1- Definition and means of variables of the 1993 inflow sample from the
\end{abstract} three Slovak districts; males

All variables are dummy variables (with value 1 where indicated and value 0 for the reference group)

\title{
Definitions of variables
}

Age<30: age is below 30 years as measured in 1998

Reference group age: age is 30 years or more in 1998

Incomplete secondary education

Secondary and higher education (including university)

Reference group education: no education - basic education - apprentice

Married: married or cohabiting person

Reference group marital status: single-divorced - widow/widower - unknown

\begin{tabular}{lllll} 
Means of variables & \multicolumn{2}{c}{ Bratislava Dolny Kubin } & \multicolumn{2}{c}{ Bardejov Total } \\
(Number of observations) & $(1499)$ & $(1902)$ & $(1656)$ & $(5057)$ \\
& & & & \\
Age < 30 years & 0.23 & 0.39 & 0.42 & 0.35 \\
Age $\geq 30$ years & 0.77 & 0.61 & 0.58 & 0.65 \\
& & & & \\
Lower education & 0.72 & 0.72 & 0.32 & 0.59 \\
Incomplete sec education & 0.06 & 0.06 & 0.40 & 0.17 \\
Sec and higher education & 0.22 & 0.22 & 0.28 & 0.24 \\
& & & & \\
Married & 0.70 & 0.58 & 0.46 & 0.58 \\
Other marital status & 0.30 & 0.42 & 0.54 & 0.42 \\
& & & & \\
Unemployment rate $(\%)$ & 4.1 & 12.9 & 19.3 & 12.4
\end{tabular}

